\title{
Zur Methodik der quantitativen Erfassung ölabbauender Bakterien in verölten Sedimenten und Böden, Ö1-Wassergemischen, Ölen und teerartigen Substanzen
}

\author{
Wilfried Gunkel und Hans-Hermann Trekel \\ Biologische Anstalt Helgoland, Meeresstation, Helgoland
}

\begin{abstract}
On the method of quantitative determination of oil decomposing bacteria in oil polluted sediments and soils, oil-water mixtures, oils and tarry substances. A method is demonstrated which makes it possible to determine the numbers of oil decomposing bacteria in substances normally unmixable with water such as oil, oil polluted soils and sediments, waxes, and tarry substances. It involves the application of a high speed homogenizer (ultra turrax), an emulsifier (non-toxic to bacteria), and a defoaming agent. After forming a fairly stable emulsion, serial dilutions with steril seawater are performed and bacterial numbers determined using the MPN (most-probable-number) technique.
\end{abstract}

\section{EINLEITUNG}

Die steigende Verwendung von Olen und Olprodukten hat dazu geführt, daß auch das Interesse an der Erdölbakteriologie von Jahr zu Jahr gewachsen ist. Neben erwünschten (Proteinsynthese aus Ol für kommerzielle $Z_{\text {wecke) }}$ und unerwünschten (zum Beispiel Wuchs von Mikroorganismen in Schneidölen und Düsenmaschinentreibstoffen) Aktivitäten auf dem industriellen Sektor, interessiert insbesondere das Vorkommen, die Verbreitung und die Leistung ölabbauender Bakterien beim Abbau von Verölungen der Gewässer und des Bodens. Hierzu sind möglichst genaue quantitative Angaben ïber die Anzahl der zum Olabbau befähigten Bakterien notwendig. Voraussetzung hierfür sind Nährböden, die selektiv nur ein Wachstum der Olabbauer gestatten.

Besondere Schwierigkeiten bereitet die Feststellung der Anzahl ölabbauender Bakterien in Altölen, Olresten, Heizölen, in teerartigen Substanzen, in Olfladen, wie sie am Strand auftreten, und in verölten Böden; kurz in Substanzen, die sich mit Wasser nicht verdünnen lassen. Organische Lösungsmittel wie Benzol scheiden wegen ihrer hohen Toxizität aus, da bei der Bestimmung der Anzahl die Vermehrungsfähigkeit als Kriterium dient und aus diesem Grunde nicht beeinträchtigt werden darf.

Nachfolgend wird eine Methode beschrieben, die es gestattet, ölabbauende Bakterien in mit Wasser ursprïnglich nicht mischbaren Substanzen quantitativ zu erfassen. Sie wurde mit Erfolg bei der bakteriologischen Bearbeitung verölter Strandsedimente nach dem Tankerunfall der "Torrey Canyon" in Cornwall sowie in Versuchen auf Helgoland eingesetzt (GUNKEL 1967). 


\section{MATERIAL UND METHODIK}

\section{Das Untersuchungsmaterial}

Als Untersuchungsmaterial, mit dem die Methode erarbeitet wurde, diente in erster Linie nasser Sand, der in einem Großversuch mit Heizöl M überschüttet wurde. Hiervon wurden nach verschiedenen Zeiten Proben entnommen. Daneben wurde das sogenannte "chocolate mousse", eine pastenförmige O1-in-Wasser-Emulsion, die sich an der Küste von Cornwall nach der Verölung durch den Tankerunfall der "Torrey Canyon" gebildet hatte, untersucht. Dieses "chocolate mousse" ist mit Wasser ebenfalls nicht mischbar. Weitere Experimente beschäftigten sich mit am Strand aufgesammelten Olfladen sowie mit asphaltartigen Olresten, die in großen Stücken an den Strand geschwemmt worden waren.

Sämtliche Materialien sind mit Wasser nicht mischbar. Dieses ist jedoch die Vorbedingung, wenn die Bakterien in Kulturmethode quantitativ erfaßt werden sollen. Aus diesem Grund wurden bisher im allgemeinen nur indirekte Techniken bei der mikrobiologischen Bearbeitung dieser Substanzen verwandt, wie z. B. Anreicherungskulturen, Messung des Sauerstoffverbrauchs, oder es wurden die Substanzen in organischen Lösungsmitteln wie z. B. Benzol aufgelöst und eine mikroskopische Untersuchung durchgeführt. Diese Lösungsmittel sind für die Bakterien im höchsten Grad giftig und rufen Abtötung hervor. Außerdem sind sie nicht mit Wasser mischbar (z. B. WANG \& SCHWARTZ 1961).

\section{Der Emulgator}

Daher wurde versucht, Mineralölemulgatoren zu einer Aufteilung der Substanzen zu verwenden. Diese Emulgatoren können OOle und Ólprodukte so fein verteilen, daß eine einwandfreie Verdünnung mit Wasser möglich ist. Der größte Teil der getesteten kommerziellen Emulgatoren besaß jedoch, insbesondere auf Grund des in ihnen enthaltenen niedrigsiedenden organischen Lösungsmittelanteils, eine so hohe Giftigkeit, daß sich eine Anwendung verbot. Der Emulgator SLM der Chemischen Werke Hüls enthielt dieses Lösungsmittel nicht. Umfangreiche Laboruntersuchungen, über die in einer der nächsten Nummern dieser Zeitschrift berichter werden soll, zeigten, daß er gegen Bakterien kaum toxisch ist. Der Emulgator besteht aus einer Mischung von Carbonsäurepolyglykolestern und Alkylolamiden. Er ist nichtionogen. Eine 1\% \% ige Mischung mit Aqua destillata besitzt nach Angaben der Herstellerfirma einen $\mathrm{pH}$ von 6,8. Er wird industriell in der Metallbearbeitung und als Textilschmälze eingesetzt.

\section{Der Homogenisator}

Zur innigen Durchmischung wurde ein Ultra-Turrax, Typ 18/2, der Firma Janke \& Kunkel, Staufen i. Br., verwandt. Es handelt sich hier um ein mechanisches Hochfrequenzgerät, das $24000 \mathrm{U} / \mathrm{min}$ leistet. Durch Hervorrufung von Druck, Be- 
schleunigungsgefälle, Stoß, Prall, Kavitation und Scherung im Medium stellt es einen vorzüglichen Homogenisator dar. Das Gerät ist hervorragend dazu geeignet, Bakterienaggregate aufzuteilen (GUNKEL 1964b).

\section{Die Gußplattenmethode}

Bei der Kultivation der ölabbauenden Bakterien lag nahe, zunächst die Gußplattenmethode zu verwenden, da diese in der Literatur öfters als hierfür geeignet angeführt wurde (z. B. Schwersfurth \& Schwille 1962). Wir verwandten DifcoBacto-Agar, angesetzt mit $750 \mathrm{ml}$ gealtertem Seewasser und $250 \mathrm{ml}$ Aqua destillata, außerdem wurden organische Stickstoff- und Phosphorsalze zugefügt. Im heißen Nährboden wurde steriles Heizöl $\mathrm{M}$ verteilt und der $\mathrm{pH}$ auf 7,6 eingestellt. Nach Eingießen von je $1 \mathrm{ml}$ der verschiedenen Proben wurde 3 Wochen bei $18^{\circ} \mathrm{C}$ bebrüter. Es bildeten sich Kolonien, die zwar gezählt werden konnten, jedoch war dieses Auszählen äußerst

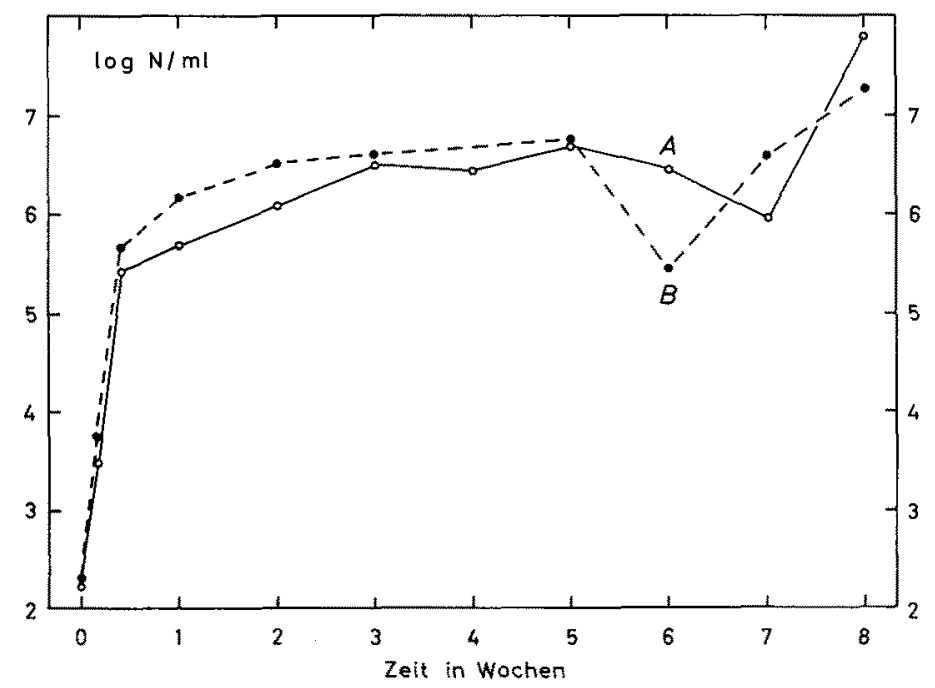

Abb. 1: Bestimmung der Anzahl vermehrungsfähiger Bakterien in einem 8 Wochen laufenden Abbauversuch. (A) Unter Verwendung eines Seewasseragarnährbodens mit Stickstoff- und Phosphorsalzen sowie mit Heizöl M. (B) Desgleichen ohne Heizöl M

mühsam, da die Kolonien sehr klein blieben und Ausfällungen von Phosphaten im Agar auftraten, die ständige Nachkontrolle mit dem Binokular erforderten. Ein Kontrollversuch schließlich zeigte, daß diese Methode für unser Material völlig ungeeignet ist, selektiv die ölabbauenden Bakterien zu erfassen. Hierzu wurde Seewasser mit seiner natürlichen Bakterienpopulation mit anorganischen Stickstoff- und Phosphorsalzen angereichert und mit Heizöl $M$ versetzt. Nach verschiedenen Zeiten wurden Proben entnommen und in das bereits angeführte Medium ausgegossen. Als Kontrolle diente ein Nährboden gleicher Zusammensetzung, jedoch ohne Olzugabe. Im ersten 
Medium sollten sich theoretisch nur solche Bakterien vermehren können, die ausschließlich auf Kosten des Ols als Energie- und Kohlenstoffquelle wuchsen, während in der Kontrolle kein Wachstum auftreten durfte, da diese Energie- und Kohlenstoffquelle fehlte. Die Ergebnisse zeigt Abbildung 1.

In der Kontrolle wuchsen nicht nur eine große Anzahl Kolonien, sondern deren Zahl war häufig sogar noch größer als in den Petrischalen mit Ol. Bei den höheren Verdünnungen, wie sie insbesondere bei der Versuchsdauer von 3 Tagen und länger verwandt wurden, ist kaum mit einer Verschleppung leichter abbaubaren, organischen Materials aus dem Original-Versuchsansatz zu rechnen. Daher muß angenommen werden, daß im Agar noch Substanzen vorhanden waren, die außer Olabbauern einen Wuchs von anderen heterotrophen Bakterien ermöglichten. Somit ist dieser Nährboden für die Erfassung der Anzahl ölabbauender Bakterien ungeeignet. Selbst eine Reinigung des Agars durch längere Wässerung hatte keinen Erfolg.

Hinzu kommen folgende Bedenken: Während des Olabbaues werden durch die Bakterien aus dem $\mathrm{O} 1$ wasserlösliche Substanzen gebildet, die von anderen Bakterien, die nicht zum Olabbau befähigt sind, ausgenutzt werden können. So muß damit gerechnet werden, daß z. B. organische Säuren im Agar von den Kolonien ölabbauender Bakterien wegdiffundieren und in ihrer Nachbarschatt im Agar liegende andere Bakterien, die sich bisher auf Grund des Mangels an von ihnen ausnutzbarer Nährstoffe nicht vermehren konnten, jetzt als leicht verwendbare Kohlenstoff- und Energiequelle zur Verfügung stehen und eine Vermehrung gestatten. Somit kann auch in den Petrischalen mit Ol im Medium mit höherer Koloniezahl als nur der Olabbauer gerechnet werden.

\section{Das Most-probable-number-(MPN)-Verfahren}

Ein Verfahren, das die Bestimmung der Anzahl vermehrungsfähiger Bakterien gestattet, ohne Agar zu verwenden, ist das sogenannte MPN-Verfahren. Es liefert die statistisch wahrscheinlichste Zahl und ist somit bedeutend genauer als die einfache Titerbestimmung nach dem Zehntelungsverfahren, das uns lediglich die Größenordnung angibt. Für ölabbauende Bakterien haben Vorosilova \& Dianova (1952) ein Zehntelungsverfahren erarbeitet, das auch zum Beispiel von RüBELT et al. (1967) verwandt wurde.

Das MPN-Verfahren wurde ursprünglich für die quantitative Erfassung coliformer Bakterien entwickelt (Standard Methods 1955), ist jedoch je nach Medium auch zur Feststellung zum Beispiel von Sulfatreduzenten, Zelluloseabbauern und Chitinabbauern gut geeignet (Gunkel \& Oppenhemer 1963, Gunkel \& Rheinheimer 1968). Das Prinzip ist folgendes: Es wird eine Verdünnungsreihe der zu untersuchenden Probe mit sterilem Seewasser in Zehnersprüngen vorgenommen. Jede nachfolgende Verdünnung besitzt nur $1 / 10$ der Anzahl an Bakterien des vorhergehenden Röhrchens, da jeweils $1 \mathrm{ml}$ bakterienhaltige Flüssigkeit zu $9 \mathrm{ml}$ steriler Flüssigkeit zugefügt wird. Aus allen diesen Verdünnungsröhrchen wird je $1 \mathrm{ml} z u$ drei bzw. fünf Parallelfläschchen gefüllt, die $10 \mathrm{ml}$ gealtertes Seewasser enthielten. Das Seewasser war mit anorganischen Stickstoffund Phosphorsalzen versetzt worden. $\mathrm{Zu}$ jeder Flasche wurde 1 Tropfen steriles 
Heizöl M zugefügt. Die Phosphate des Mediums haben die unangenehme Eigenschaft, bei einem $\mathrm{pH}$ über 7 starke Ausfällungen hervorzurufen. Da das Kriterium des Wuchses der Bakterien eine Trübung des Flascheninhalts ist, wurde, um klare Lösungen zu erhalten, der $\mathrm{pH}$ zunächst auf 6,7 eingestellt. Die Ergebnisse der damit durchgeführten Versuche waren jedoch sehr unbefriedigend, da selbst bei Aufarbeitung von Ansätzen, die stärksten Olabbau zeigten, nur sehr geringe Zahlen an Bakterien nachgewiesen werden konnten. Aus diesem Grund wurde der pH-Einfluß untersucht. Hier-

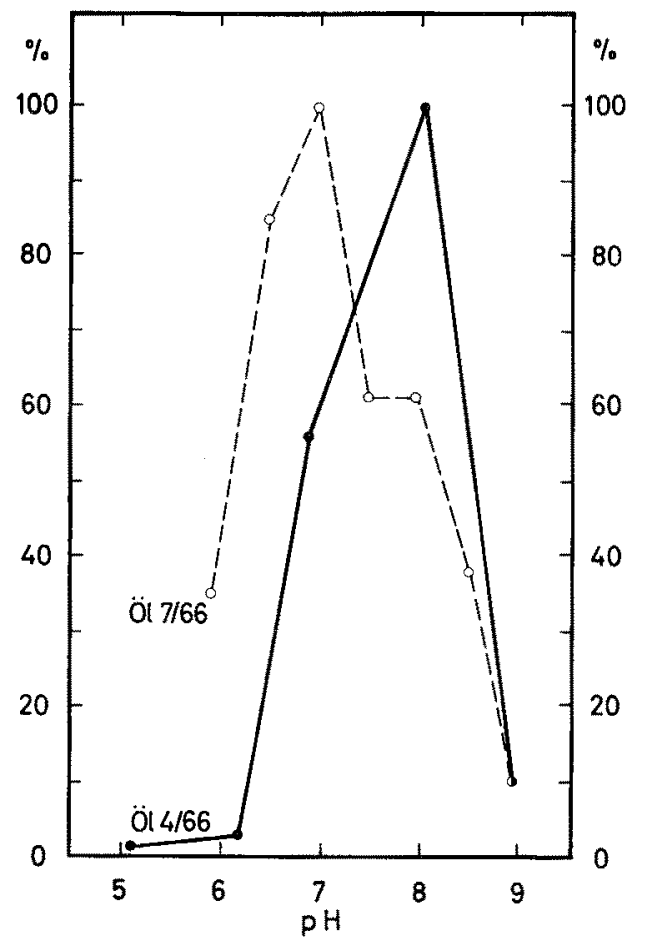

Abb. 2: Bestimmung der Anzahl ölabbauender Bakterien in einer Seewasserprobe von pH 8,01 (O1 4/66) und in einem Abbauversuch von pH 6,6 mit Hilfe der MPN-Technik. Es wurden Mehrfachbestimmungen mit Medien von verschiedenem $\mathrm{pH}$ durchgeführt. Jeweils erhaltene höchste Anzahl wurde gleich $100 \%$ gesetzt

zu wurden mehrfach Bestimmungen mit der MPN-Methode durchgeführt, wobei Nährböden mit verschiedenen pH-Werten eingesetzt wurden. Die starke Trübung bei $>$ pH 7 wurde in Kauf genommen.

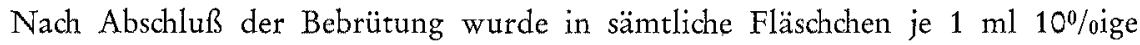
Salzsäure zugefügt, die alle anorganischen Trübungen auflöste. Die Ergebnisse sind in Abbildung 2 aufgetragen. Die erhaltene Anzahl ist als Prozent des Maximalwertes aufgeführt. Die ausgezogene Kurve (Ol 4/66) zeigt die $\mathrm{pH}$-Abhängigkeit für die Anzahl ölabbautender Bakterien einer Wasserprobe mit dem natürlichen Bakteriengehalt, die kurz vorher an der Helgoländer Kabeltonne geschöpft worden war. 
Der $\mathrm{pH}$ in situ betrug 8,01. Die höchste Anzahl der Bakterien wird bei eben diesem $\mathrm{pH}$ des Nährbodens erhalten. Bei pH 6,7 werden hier bedeutend weniger, ca. 30\% (Wert der Kurve entnommen), erhalten. Hier liegt die Erklärung für die in den ersten Versuchen erhaltene geringe Anzahl an Bakterien. In einem weiteren Versuch (Ol 7/66) wurde die $\mathrm{pH}$-Abhängigkeit der feststellbaren Bakterienzahl in einem über längere Zeit gelaufenen Abbauversuch bestimmt. Der pH betrug hier auf Grund der Anhäufung von Olabbauprodukten nur 6,6. Die Bakterienpopulation hatte sich an den bedeutend niedrigeren $\mathrm{pH}$ angepaßt. Das Maximum lag etwa bei $\mathrm{pH}$ 7. Der $\mathrm{pH}$ des Seewassers, der für den Abbauversuch verwandt wurde, lag ursprünglich bei 8, d. h. also, daß sich die Bakterien hier an diesen niedrigeren $\mathrm{pH}$ angepaßt haben. Bei $\mathrm{pH} 8$ des MPN-Nährbodens wurden nur noch ca. $60 \%$ der bei $\mathrm{pH} 7$ erhaltenen Zahlen gefunden.

\section{ERGEBNISSE}

Methode zur quantitativen Erfassung ölabbauender Bakterien und Beispiele einer Anwendung

Die gesamte Methode ist schematisch in Abbildung 3 dargestellt. Unter 1 ist die Entnahme der verölten Sandprobe angedeutet. Die Probe wird in eine sterile Flasche eingefüllt. Von uns werden 1-Liter-Plastikflaschen verwandt, die vor Benutzung mit $70 \%$ igem Alkohol sterilisiert worden sind. Die Aufarbeitung muß sich möglichst innerhalb weniger Stunden anschließen. Unter 2 ist die Vorbereitung zur Homogenisation skizziert. Von der Probe werden $2 \mathrm{ml}$ mit einer sterilen Kunststoff-Einwegspritze, deren Spitze mit einem sterilen Messer entfernt wurde, entnommen. Sie werden in eine mit $70 \%$ igem Alkohol sterilisierte 250-ml-Kunststoff-Weithalsflasche überführt, die $75 \mathrm{ml}$ sterilisiertes, gealtertes Seewasser und $25 \mathrm{ml}$ Aqua destillata enthält. $1 \mathrm{ml} \mathrm{Emul-}$ gator Hüls SLM und 1 Tropfen Entschäumer ${ }^{1}$ werden hinzugefügt. Unter 3 ist die innige Durchmischung und Aufteilung der Probe mit Hilfe des Homogenisators angedeutet. Die Einwirkungszeit von 30 Sekunden genügt normalerweise, um eine genügend stabile Emulsion zu erhalten. Den Aufbau zur Homogenisation einer "chocolate mousse"-Probe zeigt die Abbildung 4.

Von der homogenisierten Versuchsprobe wird anschließend eine Verdünnungsreihe angelegt, indem $1 \mathrm{ml} \mathrm{zu} 9 \mathrm{ml}$ sterilem Verdünnungswasser hinzugefügt wird, nach Durchmischung wird hiervon wiederum $1 \mathrm{ml} \mathrm{zu} 9 \mathrm{ml}$ sterilem Verdünnungswasser gegossen. Als Verdünnungswasser dient uns eine Mischung von $3 / 4$ gealtertem Seewasser und $1 / 4$ Aqua destillata. Versuche hatten gezeigt, daß die Zufügung von Aqua destillata keine nachteiligen Folgen hatte. Der Vorteil dieser Beimengung ist, daß keine Niederschläge beim Sterilisieren auftreten. Hierdurch wird jeweils eine Verdünnung der Bakterien auf $1 / 10$ der vorhergehenden Konzentration erreicht. Von der Ausgangsflasche und den Verdünnungsröhrchen werden jeweils drei, in manchen Fällen fünf Fläschchen mit je $1 \mathrm{ml}$ beimptt (vgl. Abb. 3 unter 4). Der Nährboden in diesen Fläschchen ist in Anlehnung an den Nährboden von IMEL.ICK (1948) (aufgeführt in BeERstecher 1954) entwickelt worden. Der Nährboden nach Imelick, der zum Bei-

${ }^{1}$ Silicon Antischaum-Emulsion SE, Wacker-Chemie, München 22. 


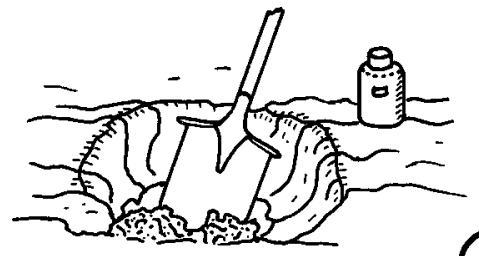

(1)

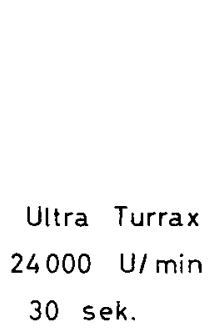

(3)

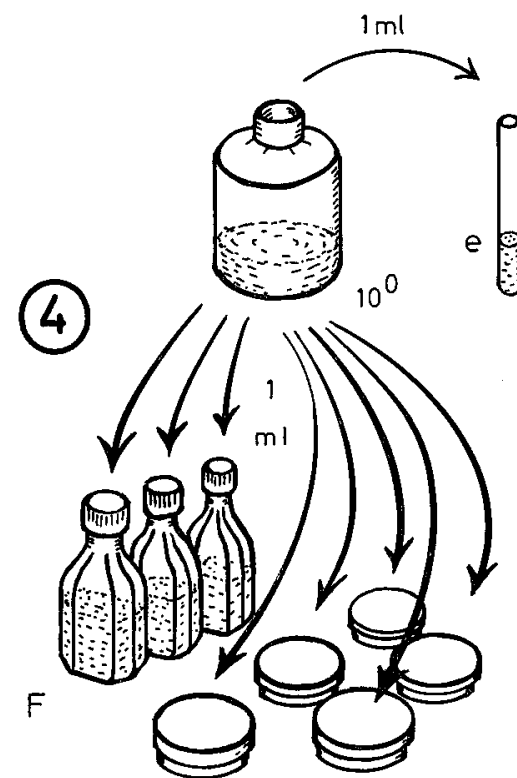

G

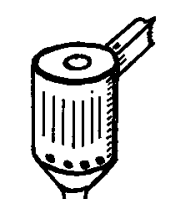

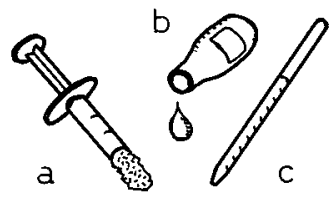

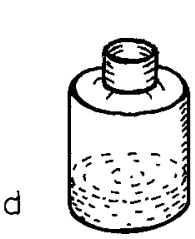

a $2 \mathrm{ml}$ Sediment c $1 \mathrm{ml}$ Emulgator

b 1 Tropfen Anti - Hüls SLM

schaummittel d $100 \mathrm{ml}$ verdünntes

Meerwasser

F MPN-Methode für olabbauende Bakterien Gussplatten - Methode für Gesamtkeimzahl

$G$ Meeresbakterien

$H$ Süsswasserbakterien

e $9 \mathrm{ml}$ verdünntes

$10^{-1}$ bis $10^{-10} \quad$ Meerwasser

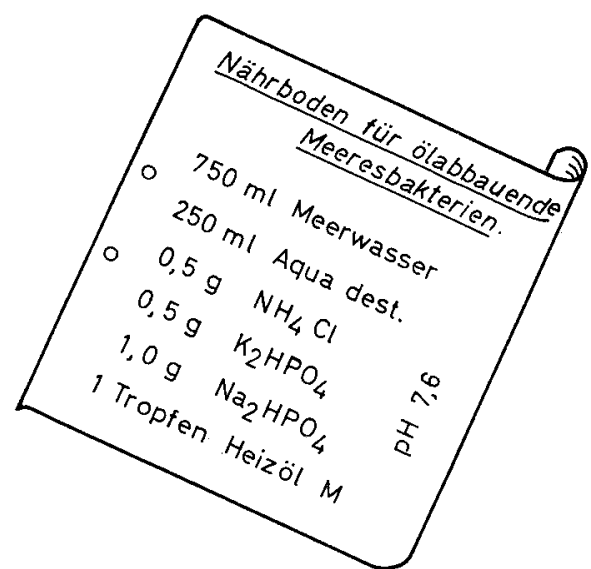

Abb. 3: Schematische Darstellung der Methode zur quantitativen Erfassung ölabbautender Bakterien 
spiel auch von Phillipps \& Traxler (1962) für ihre Untersuchungen über asphaltabbauende Bakterien verwandt wurde, hat folgende Zusammensetzung:

$\begin{array}{lr}\text { Aqua destillata } & 1000 \mathrm{ml} \\ \mathrm{MgSO}_{4} & 0,5 \mathrm{~g} \\ \mathrm{Na}_{2} \mathrm{HPO}_{4} & 1,0 \mathrm{~g} \\ \mathrm{KH}_{2} \mathrm{PO}_{4} & 0,5 \mathrm{~g} \\ \mathrm{NH}_{4} \mathrm{Cl} & 0,5 \mathrm{~g} \\ \mathrm{NaCl} & 4,0 \mathrm{~g}\end{array}$

Da Meerwasser bereits ausreichende Mengen an Natrium, Magnesium, Sulfat und Chlorid enthält, konnte der Nährboden für unsere $Z$ wecke vereinfacht werden. Außerdem wurde statt des primären Kaliumphosphats das sekundäre Salz verwandt. Er hat folgende Zusammensetzung:

$\begin{array}{lc}\text { Meerwasser } & 750 \mathrm{ml} \\ \text { Aqua destillata } & 250 \mathrm{ml} \\ \mathrm{NH}_{4} \mathrm{Cl} & 0,5 \mathrm{~g} \\ \mathrm{~K}_{2} \mathrm{HPO}_{4} & 0,5 \mathrm{~g} \\ \mathrm{Na}_{2} \mathrm{HPO}_{4} & 1,0 \mathrm{~g}\end{array}$

$\mathrm{Zu}$ jedem der kleinen Testfläschchen wurde 1 Tropfen steriles Heizöl M hinzugefügt. Der pH wurde auf 7,6 eingestellt. Als Fläschchen wurden sogenannte Meplatsflaschen mit ca. $20 \mathrm{ml}$ Inhalt verwandt, in die $10 \mathrm{ml}$ Nährboden eingefüllt wurden. Sie wurden nach Beimpfung nicht fest verschlossen, um noch einen Sauerstoffzutritt zu gestatten. Es hat sich als praktisch erwiesen, die Stickstoff-und Phosphorsalze getrennt vom Seewasser zu sterilisieren. Sie wurden in $150 \mathrm{ml}$ Aqua destillata gelöst und bildeten die Lösung A. $750 \mathrm{ml}$ gealtertes Seewasser wurde mit $100 \mathrm{ml}$ Aqua destillata versetzt und bildete Lösung B. Die Lösungen wurden nach dem Erkalten zusammengegeben.

Bei manchen Versuchen wurden gleichzeitig die heterotroph-aerob-proteolytischen Bakterien bestimmt. Hierzu dienten Medien, die einmal mit verdünntem Meerwasser, zum anderen mit Aqua destillata angesetzt worden waren. Diese Medien sind angeführt z. B. bei Gunkel $(1963,1964 a)$.

Die Bebrütung der Fläschchen erfolgte bei $18^{\circ} \mathrm{C}$ für 3 Wochen. Danach wurde zur

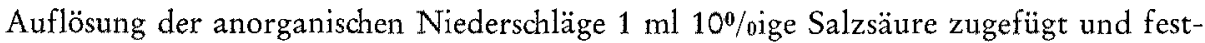
gestellt, welche Flaschen durch Bakterienwuchs getrübt waren. Die dazugehörigen Zahlen wurden den Tabellen in den Standard Methods (1955) entnommen, und unter Berücksichtigung des Verdünnungsfaktors die Anzahl ölabbauender Bakterien pro ml Ausgangsmaterial errechnet.

Abbildung 5 zeigt vier verschiedene 'Testfläschchen. Bei a handelt es sich um ein eindeutig positives Fläschchen nach Ansäuerung. Der Inhalt ist durch üppiges Bakterienwachstum milchig getrübt. Deutlich sichtbar ist auch, daß sich das $\mathrm{Ol}$ verändert hat. Das Fläschchen $b$ ist erst kürzere Zeit bebrütet und noch nicht angesäuert. Es zeigt beginnende Trübung der Flüssigkeit, auch hier hervorgerufen durch Bakterien und einen Bodensatz durch Phosphate. Auch hier ist die Konsistenz des Oles bereits verändert. c zeigt ein negatives Fläschchen. Die Flüssigkeit ist klar, ein Bodensatz von Phosphaten liegt vor. Das Fläschchen ist noch nicht angesäuert. Fläschchen d ist eben- 


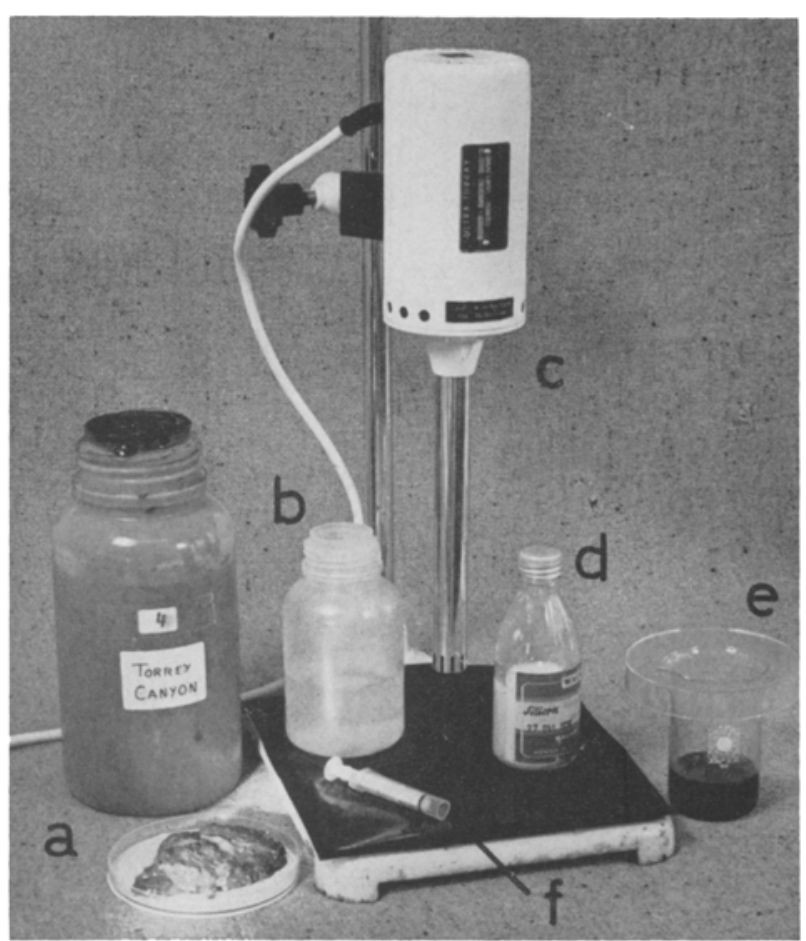

Abb. 4: Versuchsaufbau zur Emulgierung von verölten Proben. (a) Sedimentprobe, (b) Plastikflasche mit sterilem Meerwasser, (c) Ultra-Turrax Homogenisator, (d) Antischaummittel, (e) Emulgator Hưls SLM, (f) Plastik 2-ml-Spritze

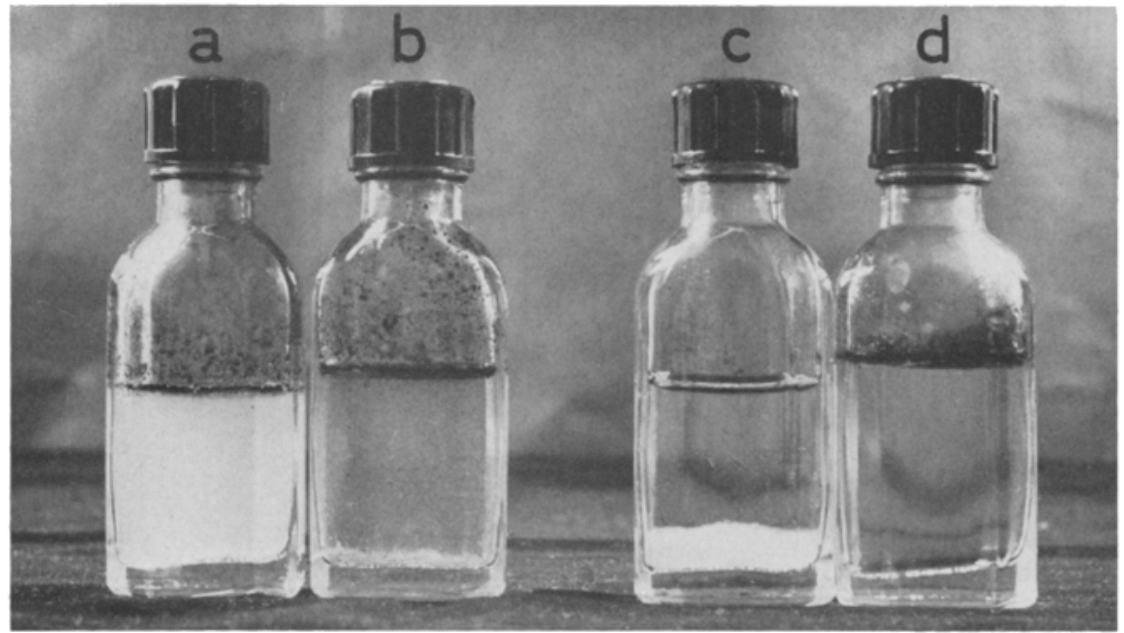

Abb. 5: Testfläschchen für die Bestimmung der Anzahl ölabbauender Bakterien. (a) positive Flasche, angesäuert; (b) beginnende Bakterientrübung, nicht angesäuert, daher noch Bodensatz von Phosphaten; (c) negative Flasche, kein Bakterienwuchs, nicht angesäuert, Bodensatz von Phosphaten; (d) negative Flasche, deren Bodensatz durch HCl-Zugabe aufgelöst wurde 
falls eindeutig negativ. Hier wurde die Ansäuerung bereits vorgenommen. Die Flüssigkeit ist völlig klar, das $\mathrm{O} 1$ unverändert.

Um die Leistungsfähigkeit der Methode zu demonstrieren, seien die Ergebnisse eines Großversuches mitgeteilt. Den Versuchsansatz zeigt Abbildung 6. Der Versuch wurde im Freigelände durchgeführt. Ein quadratischer Bohlenrahmen von $1 \mathrm{~m}$ Seitenlänge, der auf einer Sandbettung lag, wurde mit einer Suprathenfolie von 0,4 mm Stärke ausgekleidet. In dieses Becken wurden 1001 Seewasser gefüllt, die mit einer alten Anreicherungskultur versetzt wurden. In eine Ecke des Beckens wurden 3 Eimer Seesand gefüllt. Anschließend wurde auf die Wasseroberfläche $500 \mathrm{ml}$ Irak-Rohöl geschüttet. Nach 10 Tagen Standzeit wurden Proben von den in der Abbildung eingezeichneten Stellen entnommen und nach der bereits angeführten Methode aufgearbeitet.

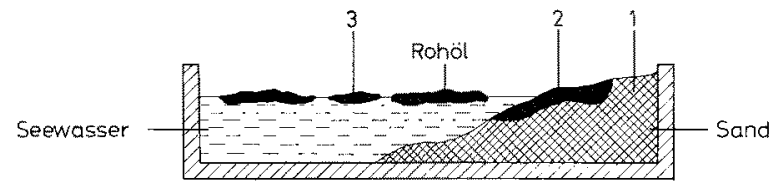

Abb. 6: Abbauversuch in einem $1 \mathrm{~m}^{2}$ großen Becken (Querschnitt). Die Strandsituation bei einer Verölung wird simuliert. Die Zahlen bedeuten Entnahmestelle für die bakteriologische Bearbeitung (siehe Text)

Die Probe 1 enthielt nichtverölten, feuchten Sand, während die Probe 2 aus ölgesättigtem, feuchtem Sand bestand. Als Probe 3 schließlich diente Ol, das von der Oberfläche des Wassers geschöpt worden war. Folgende Zahlen wurden erhalten: Probe 1 enthielt $3,8 \times 10^{4}$ ölabbauende Bakterien/ml, Probe 2 enthielt $2,4 \times 10^{7}$ ölabbauende Bakterien $/ \mathrm{ml}$ und Probe 3 enthielt 1,5 $\times 10^{6}$ ölabbauende Bakterien $/ \mathrm{ml}$. Das Ergebnis zeigt sehr deutlich den Unterschied zwischen nichtveröltem und veröltem Sand. Im verölten Sand sind nahezu tausendmal mehr ölabbauende Bakterien enthalten.

Die angeführte Methode kann in stark vereinfachter Form auch zur einwandfreien Bestimmung von ölabbauenden Bakterien in nichtverölten Wasserproben angewandt werden. Hierbei erübrigt sich der Einsatz des Homogenisators; auch Emulgator und Entschäumer brauchen nicht zugefügt zu werden. Eine Verdünnungsreihe kann hier direkt ohne weitere Vorbereitung von der Wasserprobe angelegt werden. Davon werden, wie bereits beschrieben, die MPN-Fläschchen beimpt und nach dreiwöchiger Bebrütung angesäuert und abgelesen. Mit dieser vereinfachten Methode wurden in über 100 Proben die Verbreitung ölabbauender Bakterien in der Nordsee untersucht. Die Ergebnisse werden in einem der nächsten. Hefte dieser Zeitschrift mitgeteilt werden.

\section{DISKUSSION}

In den letzten Jahren sind eine Fülle von Arbeiten zum Thema Verölung und bakterieller Olabbau erschienen. Zusammenfassende Darstellungen publizierten insbesondere ZoBell (1946), Beerstecher (1954), FuHs (1962) und Davies (1967). Von den Arbeiten, die sich mit dem bakteriellen Abbau von Olen im marinen Milieu befassen, seien ZoBel. (1964), ZoBell \& Prokop (1966) und Gunkel (1967) erwähnt. 
Fast sämtliche Veröffentlichungen, die sich mit der Bakteriologie von Olverunreinigungen beschäftigen, schildern die Verwendung von Anreicherungskulturen, von Direktzählungen nach Abtötung der Bakterien oder die Messung des Sauerstoffverbrauchs. Gelegentlich wurde die Agargußplattenmethode eingesetzt, die nach unseren Erfahrungen als Selektivnährboden für Olabbauer ungeeignet ist. Einen Fortschritt brachte die Anwendung des Zehntelungsverfahrens von Vorošilova \& Dianova (1952), das auch von Poliakova (1964) und Luchter (1966) sowie Rübelt et al. (1967) bei Untersuchungen zur Verbreitung ölabbauender Bakterien in Gewässern bzw. im Grundwasser bevorzugt wurde. Jedoch erfaßt dieses Verfahren nur die Größenordnungen der Konzentration an Bakterien.

Die hier mitgeteilte Verwendung der MPN-Technik gestattet, auch bei ölabbauenden Bakterien zu einwandfreien, definitiven Zahlenwerten zu kommen. Der Aufwand dieser Methode ist relativ groß. Pro Probe müssen ca. 30 Testfläschchen angesetzt werden. Die Mehrarbeit ist jedoch gerechtfertigt.

Die Aufteilung der mit Wasser nicht mischbaren Proben mit einem Homogenisator vom Typ Ultra-Turrax sowie Zufügung eines ungiftigen Emulgators gestattet eine einwandfreie Feststellung der Bakterien in dieser Probe. Routinemäßig wurde der Homogenisator 30 Sekunden lang eingesetzt. Eine längere Laufzeit ist möglich, jedoch kommt es dann zu einer merklichen Erwärmung der Probe, und eine Abtötung von Bakterien tritt ein. Dies kann durch Einstellung der Probenflasche in ein Eis-WasserBad während des Laufs des Homogenisators kompensiert werden (GUNKEL 1964 b). Bei den niedrigen Verdünnungen der Reihe ist eine gewisse Beeinflussung der Bakterien durch den Emulgator denkbar, nicht jedoch bei den höheren Verdünnungen, wie sie gerade bei verölten Proben vorgenommen werden müssen. Selbstverständlich werden auch in den negativen Testfläschchen einige Bakterien durch verschlepptes Probenmaterial wachsen können, da meist der Gehalt an aerob-heterotroph-proteolytischen Bakterien größer ist als derjenige an Ollabbauern. Aber erst bei einer Massenentwicklung kommt es zu einer Trübung, die das alleinige Kriterium darstellt. Zweifelsfälle, ob ein Testfläschchen als positiv anzusehen ist oder nicht, traten bei uns fast nie auf. Eine Nachkultur gab in solchen Fällen eindeutige Antwort.

Zur Zeit führen wir Untersuchungen durch, ob nicht andere Emulgatoren, die besonders schwer abbaubar sind, noch besser für diese Methode geeignet sind. Die geschilderte Methode ist sehr brauchbar für die Erfassung ölabbauender Bakterien in verölten Proben. In nichtverölten Wasserproben ist der Einsatz des Homogenisators und des Emulgators nicht notwendig.

\section{ZUSAMMENFASSUNG}

1. Eine neue Methode wird beschrieben, die es gestattet, die Anzahlen ölabbauender Bakterien in mit Wasser nicht mischbaren Substanzen wie verölte Sedimente, verölter Boden, verharzte Altöle, Rohöle, Schmieröle und Ol-Wassergemische quantitativ zu erfassen.

2. Die Olproben werden in sterilem Meerwasser mit einem mechanischen Hochfrequenzgenerator „Ultra Turrax“ der Type TP 18/2 (30 Sekunden Laufzeit) nach Zufügung eines für Bakterien nicht toxischen Emulgators sowie eines Entschäumers aufgeteilt. 
3. Die zu untersuchende Emulsion wird nach dem Zehntelungsverfahren unter Verwendung sterilen Meerwassers verdünnt.

4. Jeweils mehrere Testfläschchen werden aus jeder Verdünnungsstufe beimpft, die als Nährboden mit anorganischen Stickstoff- und Phosphatsalzen supplementiertes, gealtertes Meerwasser und $O 1$ als einzige Kohlenstoff quelle enthalten.

5. Die Bebrütung dauert 3 Wochen (bei $18^{\circ} \mathrm{C}$ ). Dann wird mit Salzsäure angesäuert, um anorganische Niederschläge aufzulösen. Die bakterielle Trübung wird ermittelt, und die dazugehörigen Bakterienzahlen werden aus den Tabellen der MPN-Methode (Most-probable-number-Verfahren) entnommen.

Besonderer Dank gebührt der BP Olgesellschaft A.G., Hamburg, und der British Petroleum Comp. Ltd., London, die die Arbeit maßgeblich unterstützten. Herrn Dr. Bock, Chemische Werke Hüls, Marl, danken wir für die Bereitstellung des Emulgators und für Beratung. Gewissenhafte Hilfe bei der Durchführung der Experimente leistete Herr R. KöHN, Helgoland.

\section{ZITIERTE LITERATUR}

American Public Health Association, 1955. Standard methods for the examination of water, sewage and industrial wastes. 10 th ed. A.P.H.A., New York, 522 pp.

Beerstecher, E., 1954. Petroleum microbiology. Elsevier, Ansterdam, 375 pp.

Davies, J. B., 1967. Petroleum microbiology. Elsevier, Amsterdam, 604 pp.

Funs, J. W., 1961. Der mikrobielle Abbau von Kohlenwasserstoffen. Arch. Mikrobiol. 39, $374-422$.

Gunk.EL, W., 1963. Daten zur Bakterienverteilung in der Nordsee. Veröff. Inst. Meeresforsch. Bremerh. (Sonderbd. 1), 80-89.

- 1964a. Einwirkungen des kalten Winters 1962/63 auf die Bakterienpopulationen vor Helgoland. Helgoländer wiss. Meeresunters. 10, 246-256.

- 1964b. Die Verwendung des Ultra-Turrax zur Aufteilung von Bakterienaggregaten in marinen Proben. Helgoländer wiss. Meeresunters. 11, 287--295.

- 1967. Experimentell-ökologische Untersuchungen über die limitierenden Faktoren des mikrobiellen Olabbaues im marinen Milieu. Helgoländer wiss. Meeresunters. 15, 210-225.

- \& Oppenhermer, C. H., 1963. Experiments regarding the sulfide formation in sediments of the Texas Gulf Coast. In: Symposium on marine microbiology. Ed. by C. H. Oppenheimer. C. C. Thomas, Springfield, Ill., 674-684.

- \& Rheinheimer, G., 1968. Bakterien. In: Methoden der meeresbiologischen Forschung. Hrsg. von C. Schlieper. VEB-Fischer, Jena (im Druck).

LuCHTER, A., 1966. Untersuchungen über Kohlenwasserstoff oxydierende Bakterien im Wasser der Wisla. In: Vorträge des internationalen Symposiums „Erdölmikrobiologie“, Brno (CSSR), 5.-7. 10. 1964. Hrsg. von I. Malek \& W. Schwartz. Akad,-Verl., Berlin, 240 pp.

Polrakova, I. N., 1962. Distribution of microorganisms oxydizing hydrocarbons in the water of the Neva inlet. Mikrobiologija 31 (6), 1076-1081.

RüBett, Ch. \& SCHWEISFuRTH, R. \& ZIMMERMANN, W., 1967. Experimentaluntersuchungen über die Verschmutzung von Grundwasser durch Mineralölprodukte. T. 2. Gas- $u$. Wasserfach $108(32), 893-900$.

Schweisfurth, R. \& SChwllLe, F, 1962. Untersuchungen über einen Fall von Untergrundverunreinigung durch Dieselkraftstoff. II. Mikrobiologische Untersuchungen. Wass. Abreass. (7), 170-172,

Vorošrlova, A. A. \& Dranova, E. V., 1952. Erdöloxydierende Bakterien als Gradmesser der Intensität der biologischen Oxydation des Erdöls unter natürlichen Bedingungen. A. d. Russ. Mikrobiologija 21 (4), 408-415. 
Wang, H. \& Schwartz, W., 1961. Untersuchungen zur Mikrobiologie des Erdöls und der Erdölprodukte. IV. Mikrobiologische Untersuchung eines Ölfeldes. Z. allg. Mikrobiol, 1, 223-244.

ZoBell, C. E., 1964. The occurrence, effects and fate of oil polluting in the sea. In: Advances in water pollution research. Vol. 3. Ed. by E. A. Pearson. Pergamon Press, Oxford, 85-119.

ZoBeld, C. E. \& Prokop, J. F., 1966. Microbial oxidation of mineral oils in Barataria Bay bottom deposits. $Z$. allg. Mikrobiol. 6, 143-162. 